\title{
Biochemical and Gene Expression Involved in Red Blush Color Development in 'Ambrosia' Apple
}

\author{
Peter M.A. Toivonen ${ }^{2}$, Jared Stoochnoff ${ }^{1}$, Kevin Usher, Changwen Lu, and Paul A. Wiersma \\ Agriculture and Agri-Food Canada, Summerland Research and Development Centre, Summerland, \\ $B C$, Canada $\mathrm{VOH} 1 \mathrm{ZO}$ \\ Chunhua Zhou \\ College of Horticulture and Plant Protection, Yangzhou University, Yangzhou, Jiangsu Province, \\ 225009, P. R. China and the Joint International Research Laboratory of Agriculture \& Agri-Product \\ Safety, Yangzhou University, Yangzhou, Jiangsu Province, 225009, P. R. China
}

\begin{abstract}
AdDitional INDEX words. fruit color, anthocyanin biosynthesis, MYB transcription factors, controlled environment chambers

Abstract. The market value of the apple (Malus $\times$ domestica Borkh.) cultivar Ambrosia is closely linked to the characteristic blush on the skin surface. For 'Ambrosia' orchards that produce consistently low levels of surface blush, the implementation of reflective rowcovering has improved surface coloration, but the reflected wavebands responsible for this enhanced color production have not been confirmed. This study consisted of two separate experiments: one conducted in the field to confirm reflective rowcovering efficacy and the other in a controlled environment cabinet to determine which waveband was enhancing red blush production. The red blush production in orchards with and without reflective rowcovering was then directly compared with the red blush produced on the surface of apples that were poorly colored at harvest and then exposed to visible, fluorescent, ultraviolet A (UVA), or ultraviolet B (UVB) light sources within the controlled environment chamber. Consequent analysis of the red blush color within the Commission Internationale de l'Eclairage $a^{*}$ and $b^{*}$ color space was conducted to evaluate the quality of the red blush pigment under each treatment in the field and the controlled environment chamber. The analysis revealed that the red blush that developed on apples from the reflective rowcover treatment most closely matched the red blush that developed in response to UVB exposure in the controlled environment cabinet. Further analysis of gene expression and anthocyanin contents in the 'Ambrosia' apples support the hypothesis that the primary driver for the characteristic red blush development, when reflective rowcovers are used, is increased exposure to UVB light.
\end{abstract}

'Ambrosia' is becoming a popular apple cultivar on the global fruit market that is easily recognized for its characteristic red blush and creamy yellow background (Cline, 2009). This visual attraction is an important factor in gaining consumer attention and is therefore an important determinant of market value (Ritenour and Habib, 1997). Unfortunately, it is difficult to produce 'Ambrosia' apples with sufficient red coloration to meet this requirement in some growing locations (Toivonen et al., 2018). It is possible to increase color by delaying harvest, but this is often detrimental to overall fruit quality and storability (Toivonen et al., 2018). Over-mature apples soften quickly, can abscise from the tree before harvest, and cannot withstand long-term controlled atmosphere (CA) storage (Kvikliene et al., 2008). Therefore, new management strategies need to be developed that can accelerate red blush coloration within poorly colored orchards to

\footnotetext{
Received for publication 4 Dec. 2018. Accepted for publication 25 Feb. 2019. The authors are grateful for the financial support of this work jointly by the British Columbia New Varieties Development Council and Agriculture and Agri-Food Canada's Agri-Innovations Program. We also thank the Excellent Youth Backbone Teacher Program of Yangzhou University and the Public Study Abroad Program of Yangzhou University for the Visiting Scientist Scholarship to support Dr. Zhou's travel and work at the Summerland Research and Development Centre.

${ }^{1}$ Current address: Controlled Environment Systems Research Facility, Ontario Agricultural College, University of Guelph, Guelph, Ontario, Canada

${ }^{2}$ Corresponding author. E-mail: peter.toivonen@canada.ca.
}

coincide with an optimal time of harvest (Ritenour and Habib, 1997).

To develop management practices that amplify red blush coverage, it is important to understand the biochemical and molecular bases of red blush production. Anthocyanin, a member of the flavonoid family, is responsible for the red blush observed on the surface of apple skin and is a natural pigment found in many fruits, berries, leaves, and flowers (Castañeda-Ovando et al., 2009). Cyanidin-3-galactoside, an anthocyanin derivative, has been identified as the primary pigment in fruit of many red apple cultivars (Tsao et al., 2003). However, the identity of the primary anthocyanin derivative in 'Ambrosia' skin has not been determined. Biosynthesis of apple anthocyanins is controlled at the level of gene expression by the transcription factor MdMYB1 [Takos et al., 2006 (also called MdMYBA in Ban et al., 2007)] in cooperation with bHLH and WD40 transcription factors (Espley et al., 2007). This MYB gene also produces a red-fleshed phenotype in apple through the allelic variant MdMYB10 (Espley et al., 2007; Zhang et al., 2014).

Anthocyanin primarily accumulates in the vacuoles of epidermal and hypodermal cells and therefore is one of the first compounds to interact with incident light on the fruit surface (Solovchenko, 2010). The molecular structure of anthocyanin consists of three conjugated rings, with a delocalized positive charge, attached to a glycoside moiety (Castañeda-Ovando et al., 2009). The conjugated ring structure of anthocyanin 
grants it the ability to attenuate incident light intensity and thereby functions as a sunscreen preventing excess light from photo-inhibiting chloroplasts in the peel tissue or damaging sensitive mesocarp tissue (Solovchenko, 2010). The delocalized positive charge within the conjugated ring structure, known as the flavylium ion, also allows the ability to act as an antioxidant to mop up any free radicals created by photosynthesis and photo-inhibition (Wolfe et al., 2003).

Anthocyanin production in apples is influenced by light conditions, temperature, and nutrient availability (Ritenour and Habib, 1997) as well as ethylene (Honda et al., 2014). Red blush color generation in 'Ambrosia' coincides with seasonal decreases in temperature and daylength (Cline, 2009). 'Ambrosia' is an apple that does not exhibit a climacteric rise in ethylene production at or near the time of commercial harvest maturity (Cline, 2009) and so ethylene effects on anthocyanin synthesis are not likely of relevance for this apple cultivar.

Because anthocyanin biosynthesis is sensitive to light conditions, variation in red blush production observed between orchards in similar microclimates may be due to variation in light exposure. Therefore, increasing light intensity and area of exposure on the fruit surface has potential to increase the red blush color (Reay and Lancaster, 2001). One method of amplifying light intensity and exposure in an orchard setting is to lay out reflective rowcover. Installing a reflective cover can increase the cumulative intensity reaching the fruit surface and expose fruit surface that are otherwise shaded within the canopy (Ritenour and Habib, 1997).

While reflective rowcovers have been very effective in improving red blush development in apples, very little research has been done to evaluate the specificity of light wavelength bands involved in the response for apple other than examine the effect of the rowcover on photosynthetically active radiation $(P A R)$ in the orchard (Bassett and Glenn, 2014; Privé et al., 2008). Some research suggests that UVB exposure may be important to induce anthocyanin biosynthesis in red apple cultivars (Reay and Lancaster, 2001; Ubi et al., 2006), but no work has been done to evaluate the effect of reflective rowcovers on ultraviolet reflectance and consequent association with red blush development on the apple. The mechanism by which plants detect UVB light has recently been shown to involve the UVR8 receptor in cooperation with COP1 and HY5 (Singh et al., 2014; Yin et al., 2016). The response to altering the light environment in the orchard to enhance red blush in 'Ambrosia' apples can be evaluated at the gene expression level to better understand the relative importance of UVA and UVB light and the mechanism driving the accumulation of anthocyanins in the peel of this apple cultivar. The UVA waveband is defined as between 320 and $400 \mathrm{~nm}$ and the UVB waveband is defined as between 280 and $320 \mathrm{~nm}$ (Kollias et al., 2011).

To elucidate the importance of ultraviolet reflectance on the efficacy of the reflective rowcover to induce red blush development in Ambrosia apple, two experiments were conducted. The first was a comparative experiment evaluating the red pigment accumulation in both $\mathrm{CA}$ chamber and orchard experiments with or without reflective rowcovers. The chamber experiments consisted of chambers supplemented with UVA, UVB, fluorescent lights (which emit visible and ultraviolet wavebands), or visible light only. The second experiment involved sampling apple peel for anthocyanins (red pigments) and flavonols (secondary compounds in the anthocyanin pathway), over time in the orchard, after application of re- flective rowcovers. The apple peel tissues were also sampled for expression of genes important to ultraviolet response and to regulation of genes associated with the anthocyanin pathway (CHS, CHI, F3H, DFR, LDOX, UFGT, MYB1, MYB8, UVR8, bHLH3, bHLH33, COP1, and HY5).

\section{Materials and Methods}

Preharvest treatments in the orchard. A commercial 'Ambrosia' apple orchard in Cawston, BC, Canada was selected, and the coordinates were lat. $49.18^{\circ} \mathrm{N}$ and long. $119.74^{\circ} \mathrm{W}$. The orchard consisted of 12 -year-old healthy trees trained in a super spindle system and managed following British Columbia production recommendations. The rows were oriented east-west, and the 2.7-m-tall super spindle trees were supported with a three-wire trellis anchored to $2.4-\mathrm{m}$-tall posts. The trees were spaced $0.45 \mathrm{~m}$ apart in 3-m-wide rows on an 'M.9' rootstock. The mature trees formed a fruiting wall on feathered branches that extended the canopy $0.6 \mathrm{~m}$ out from the main trunk in midsummer. The super spindle training system was maintained with summer pruning at 8 to 10 weeks after full bloom, and the fruit were thinned so that there were 40 to 50 apples per tree. For the reflective rowcover treatment, a 2-mwide white woven polyethylene reflective rowcover (Extenday; Extenday New Zealand, Auckland, New Zealand) was installed on either side of each selected row 4 weeks before the estimated harvest date. The rowcover was laid over grass on both sides of the treatment row and tethered to tree trunk bases with bungee cords to prevent lifting by the wind. The control row was chosen several rows away from rowcover treatment rows to mitigate potential confounding due to altered light reflection in rows adjacent to those having a reflective cover. Each experimental row of 'Ambrosia' trees was divided into three blocks, each consisting of 15 trees. Spacing between trees was $\approx 0.3 \mathrm{~m}$ at each orchard. Irrigation, fertilization, and pest control schedules applied by the grower were applied identically for both the control and treatment rows throughout the experiment.

Orchard light and temperature conditions were monitored throughout the experiment. PAR sensors (LI-190 Quantum Sensor; LI-COR, Lincoln, NE) were deployed at $1 \mathrm{~m}$ height in the canopy to log light intensity throughout the experiment. Data loggers (HOBO U23 Pro v2 Temperature/Relative Humidity Data Logger; Onset Computer Corp., Bourne, MA) were deployed to measure temperature at $1 \mathrm{~m}$ height in the orchard tree canopy throughout the experiment. Accumulated hours of temperatures below $17^{\circ} \mathrm{C}$ during daylight hours were calculated because response to ultraviolet light requires or is enhanced by cooler temperatures (Reay and Lancaster, 2001; Ubi et al., 2006). Daylight was defined as when instantaneous $P A R$ measurements were greater than $5 \mu \mathrm{mol} \cdot \mathrm{m}^{-2} \cdot \mathrm{s}^{-1}$. A portable spectroradiometer (LI-1800, LI-COR) was used to make comparative measures of spectral reflectance in the tree canopy between reflective rowcover and control treatments in the field on specified days. The spectroradiometer sensor head was placed at $1 \mathrm{~m}$ and positioned at a $45^{\circ}$ angle toward the grass or rowcovering to measure light reflection into the canopy from the row. The spectroradiometer sensor head was shrouded to eliminate potential of direct incident sunlight artifacts for the readings.

Fruit maturity was assessed by using the Cornell starch clearing chart (Blanpied and Silsby, 1992). Fruit were harvested on 29 Sept. when the average starch clearing index of 15 apple samples (one from each tree) reached $3.7 \pm 0.8$ (Blanpied and 
Silsby, 1992). Fruit was harvested by hand into soft-sided picking bags from three spatially separated blocks of 15 trees for each treatment and carefully transferred to stackable polyethylene crates of 35-L capacity. A total of 60 apples from each replicate of each treatment were harvested and transported to the laboratory within $2 \mathrm{~h}$ of harvest. The intensity of red blush coloration was assessed on 15 apples from each replicate of the reflective rowcover and control treatments, using a chroma-meter (CR400/410; Konica Minolta, Ramsey, NJ) and assigned to a color space using the $\mathrm{a}^{*}$ and $\mathrm{b}^{*}$ values according to the Commission Internationale de l'Eclairage (CIE) color system.

COMPARISON OF ORCHARD LIGHT TREATMENT EFFECTS ON RED BLUSH FORMATION TO THE BLUSH FORMED ON POORLY COLORED APPLES AFTER EXPOSURES TO UVA, UVB, Visible, OR FLUORESCENT LIGHT WITHIN A CONTROLLED ENVIRONMENT CABINET. Another 120 'Ambrosia' apples not having appreciable blush color, as determined visually, were harvested on 29 Sept. from a different nearby commercial orchard of similar characteristics to those described for the previous orchard, at an average Cornell starch clearing chart index of $3.2 \pm 0.6$ (Blanpied and Silsby, 1992) for 15 randomly chosen apple samples. These apples were held at $0.5{ }^{\circ} \mathrm{C}$ in air storage until ultraviolet light experiments were conducted. All ultraviolet light experiments were conducted in growth chambers (Controlled Environments, Winnipeg, MB, Canada) set at $16{ }^{\circ} \mathrm{C}$ since response to ultraviolet light is enhanced at this lower temperature (Reay and Lancaster, 2001). Apples were exposed to constant $32 \mu \mathrm{mol} \cdot \mathrm{m}^{-2} \cdot \mathrm{s}^{-1}$ of UVA $(356 \mathrm{~nm})$ or $0.5 \mu \mathrm{mol} \cdot \mathrm{m}^{-2} \cdot \mathrm{s}^{-1}$ of UVB (302 $\mathrm{nm})$ by adjusting the distance between the lamp and fruit to achieve the desired ultraviolet photon flux density at the fruit surface. The intensities used in this experiment were determined in preliminary experiments that were conducted to identify the photon flux density value that maximized the rate of red blush development for each ultraviolet band, without causing injury to the peel tissue. The intensity of the ultraviolet was quantified using an ultraviolet sensor sensitive to both UVA and UVB wavebands (model SU-100; Apogee Instruments, Logan, UT). The visible light control was achieved by masking the apple surface with ultraviolet-absorbing polycarbonate lenses (Virtua Safety Glasses; 3M, St. Paul, MN) to prevent exposure of the peel to ultraviolet light emitted by the fluorescent light tubes of the growth chamber (Philips 56W, T8, High Output fluorescents; Philips Lighting Canada, Markham, ON, Canada), which emit light primarily in the range of 400 to $720 \mathrm{~nm}$. However, fluorescent tubes are known to emit significant UVA and UVB irradiation (Klein et al., 2009) and the measured UVA+UVB photon flux density from these tubes was measured as $1.5 \mu \mathrm{mol} \cdot \mathrm{m}^{-2} \cdot \mathrm{s}^{-1}$.

Red blush color development was monitored using a chroma-meter (Konica Minolta), recording $\mathrm{a}^{*}$ and $\mathrm{b}^{*}$ values of the CIE color system. To measure the same area consistently, black circles the size of the Minolta sensor head were drawn with an indelible marker on the apple surface. The surface of the apples measured for the orchard and growth chamber experiments was the most dense red-blush-colored area of the fruit. In the case of the apples from the orchard treatments, this surface was the southern exposure surface, and in the case of the growth chamber experiments, it was the surface directly exposed to the light source. The specific light exposure treatments in the growth chambers (UVA, UVB, fluorescent light, and visible light only) were compared with each other and against apples from the orchard control and reflective rowcover treatments on a two-dimensional color space plot of $\mathrm{a}^{*}$ and $\mathrm{b}^{*}$ coordinates of the color measurements. Measurements were taken from three replicates of each treatment, each consisting of 15 apples (Konica Minolta, 2017).

FlaVONOL AND ANTHOCYANIN ACCUMULATION OVER TIME IN THE ORCHARD IN RESPONSE TO REFLECTIVE ROWCOVERS AND ITS ASSOCIATION WITH GENE EXPRESSION. This experiment was conducted to determine whether there was a differential pattern for anthocyanin and flavonoid accumulation in apple peel from blocks subjected to the reflective rowcover treatment vs. control blocks not having reflective rowcovers. Apples for peel tissue were collected at another nearby commercial orchard on three dates (19 and 26 Sept. and 3 Oct.). The commercial harvest date for this second orchard was 26 Sept. when the starch clearing values were $4.0 \pm 0.5$ (Blanpied and Silsby, 1992). The experimental design and row orientation in this orchard was identical to that reported in the first orchard experiment. Although there were 15 trees in each of three experimental blocks, only two apples were collected from each of three trees within an experimental block. The result was that there were three biological replicates collected, each consisting of a combined sample of the peels of six apples per replicate. The apples that were sampled were selected to be fruit that were within the outer canopy area to ensure that sampling location did not influence the results. Once harvested and returned to the laboratory, apples were uniformly peeled using a commercial apple peeler. Once the fresh weight of the peel was recorded, liquid nitrogen was applied to freeze the fresh peel. The frozen peel was then powdered using a liquid nitrogen freezer mill (SPEX Certiprep, Metuchen, NJ). Half of the powdered sample was reserved for subsequent gene expression analysis, and a part of the frozen powdered peel tissue was dried in a freeze-drier (VirTis 50-SRC lyophilizer; SP Scientific Industries, Warminster, PA) for subsequent analysis of anthocyanins and flavonols.

Total RNA was extracted by a small-scale modification of the cellulose binding method described in Wiersma et al. (2007). Sample size was reduced to two aliquots of $\approx 100 \mathrm{mg}$ for each sample, solutions were reduced in proportion, centrifugation was done in an Eppendorf microcentrifuge, and washing of the cellulose was done on a vacuum manifold. cDNA synthesis was as in Wiersma et al. (2007) and real-time polymerase chain reaction was done in a CFX96 using SsoFast EvaGreen master mix according to the manufacturer's instructions (Bio-Rad, Hercules, CA). Primers for apple actin (AB638619.1) were used for normalization, and the amplifications for all samples with this actin primer set were tightly clustered within 1.5 Cqs. Relative transcript abundance for each gene is given as the average of three biological replicates per treatment at each time point relative to the "week one control Rep2" sample, which was included on all plates and normalized to actin expression (Pfaffl, 2001).

QuANTIFication of ANTHOCYANins AND Flavonols. Half a gram of powdered apple skin was placed into a 50-mL capped test tube containing $30 \mathrm{~mL}$ of a solution of methanol, Milli-Q [Millipore (Canada), Etobicoke, ON, Canada] water and acetic acid in a ratio of 55:35:10. The mixture was placed on a shaker table for $30 \mathrm{~min}$ at room temperature. The mixture was then sonicated for $5 \mathrm{~min}$ in a $40{ }^{\circ} \mathrm{C}$ water bath. The sample was subsequently centrifuged at $20,000 \mathrm{~g}_{\mathrm{n}}$ for $12 \mathrm{~min}$. The supernatant was transferred into a clean, dry, round-bottom flask. The process was repeated twice to ensure efficacy of extraction. After the third extraction repetition, the three supernatants were 
mixed and transferred to a round-bottom flask. The combined supernatants in the round-bottom flasks were concentrated using a rotary evaporator to remove excess solvent. The rotary evaporator water bath was kept at $40{ }^{\circ} \mathrm{C}$. The samples took $\approx 30$ min to become relatively dry. The product was resuspended in extraction solvent in a $5-\mathrm{mL}$ volumetric flask. Finally, $1 \mathrm{~mL}$ of the concentrated apple skin extract solution was filtered using $0.45-\mu \mathrm{m}$ syringe filters $(13 \mathrm{~mm}$ Chromospec ultraviolet nylon Syringe Filters; Chromatographic Specialties, Brockville, ON, Canada) into a clean amber high-pressure liquid chromatograph (HPLC) vial.

HPLC-Diode-ARRAY detector CONDitions. Apple skin extracts were analyzed with an HPLC-diode-array detector (1100 series; Agilent Technologies, Santa Clara, CA) using a Zorbax SB-C18 column $(5 \mu \mathrm{m}, 3.0 \times 250 \mathrm{~mm}$, Agilent Technologies $)$ and guard column $(5 \mu \mathrm{m}, 12.5 \mathrm{~mm} \times 4.6 \mathrm{~mm}$, Agilent Technologies). Anthocyanins were separated by gradient with eluants $\mathrm{A}: 95 \% 50 \mathrm{~mm} \mathrm{H}_{3} \mathrm{PO}_{4}(\mathrm{v} / \mathrm{v})$ and $\mathrm{B}: 5 \%$ methanol (v/v) at a flow rate of $0.4 \mathrm{~mL} \cdot \mathrm{min}^{-1}$. The gradient for eluant $\mathrm{B}$ was: $5 \%$ from 0 to $5 \mathrm{~min}$ then $5 \%$ to $55 \%$ over 5 to $51 \mathrm{~min}$. Anthocyanins were detected at $525 \mathrm{~nm}$. Flavonols were separated by gradient with eluants A: $88 \% 50 \mathrm{~mm} \mathrm{H}_{3} \mathrm{PO}_{4}(\mathrm{v} / \mathrm{v})$ and $\mathrm{B}: 12 \%$ acetonitrile $(\mathrm{v} / \mathrm{v})$ at a flow rate of $0.4 \mathrm{~mL} \cdot \mathrm{min}^{-1}$. The gradient for eluant B was $12.0 \%$ to $13.9 \%$ from 0 to $7 \mathrm{~min}, 13.9 \%$ to $20 \%$ from 7 to $9 \mathrm{~min}, 20 \%$ to $23.2 \%$ from 9 to $25 \mathrm{~min}$ and $23.2 \%$ to $50 \%$ from 25 to $26 \mathrm{~min}$. Flavonols were detected at $360 \mathrm{~nm}$.

Phenolic standards. The anthocyanin external standards cyanidin-3-galactoside and cyanidin-3-glucoside were purchased from Sigma-Aldrich (St. Louis, MO). The flavonol standard quercetin-3-galactoside was purchased from Extrasynthese (Genay, France). Identification of apple anthocyanins and flavonols was based on spectral data, standards, and comparisons of retention times from published data (Borges et al., 2010) between cranberry (Vaccinium macrocarpon Ait.) and apple extracts.

Statistical analysis. Color space coordinates $\left(a^{*}\right.$ and $\left.b^{*}\right)$ were in a two dimensional color space graph, where a* values were represented on the $\mathrm{x}$-axis and $\mathrm{b}^{*}$ values on the $\mathrm{y}$-axis. Mean values of $a^{*}$ and $b *$ for each treatment were plotted on the color space graph with standard errors for $\mathrm{a}^{*}$ and $\mathrm{b}^{*}$ represented by horizontal and vertical error bars, respectively.

Changes in anthocyanin, flavonol content, and transcript levels in response to reflective rowcover treatment and duration of treatment were evaluated as a two treatments $\times$ three durations factorial design. Statistical analysis was performed using SAS General Linear Models procedure (SAS Institute, Cary, NC). Results are presented as means and SEs of the means in line graphs or bar graphs. Changes in relative gene expression evaluated using Duncan's new multiple range test at $\alpha=0.05$.

\section{Results and Discussion}

Orchard rows with reflective rowcovering had several-fold higher reflected irradiance within the canopy compared with the control treatment (Fig. 1). The greatest levels of enhanced reflectance occurred between 330 to $750 \mathrm{~nm}$ (Fig. 1). Most of the UVA waveband is included in this spectral radiance measure in the canopies of the two treatments [Fig. 1 (inset)]. As a result, the total daily exposure to $P A R$ was consistently several-fold higher in the reflective rowcover treatment throughout the entire experiment duration (Fig. 2). The finding

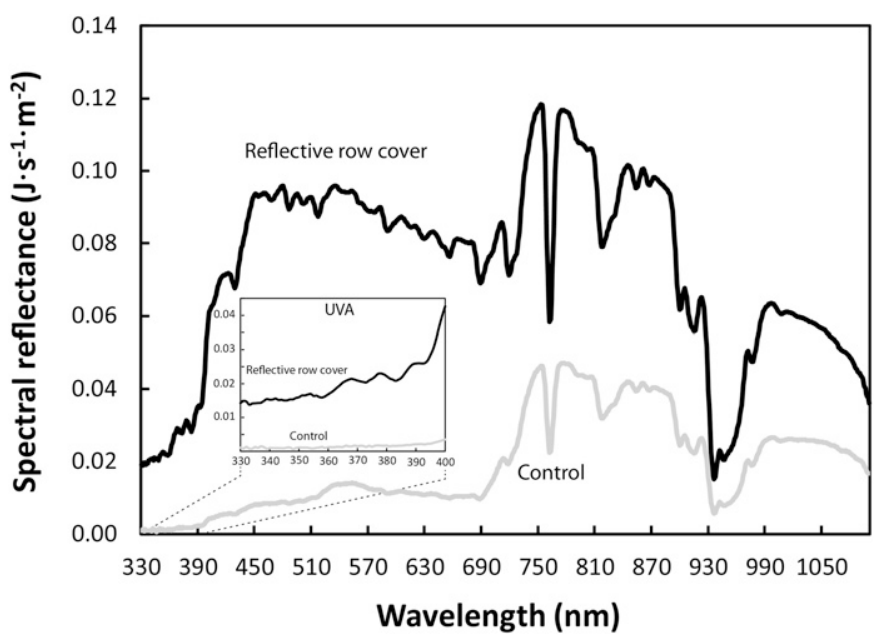

Fig. 1. Spectral reflectance at $1 \mathrm{~m}$ height in the canopy of a commercial 'Ambrosia' apple orchard for trees within a reflective rowcover treatment or for trees in an area where no reflective rowcover was applied (control). Measurement was made at $1100 \mathrm{HR}$ on 19 Sept. 2014. Measurement was made with a portable spectrometer (LI-1800; LI-COR, Lincoln, NE) fitted with a quartz fiber-optic probe and the sensor head was directed at a $45^{\circ}$ angle toward the middle of the adjacent row and was shrouded to prevent interference by direct sunlight impingement on the sensor head.

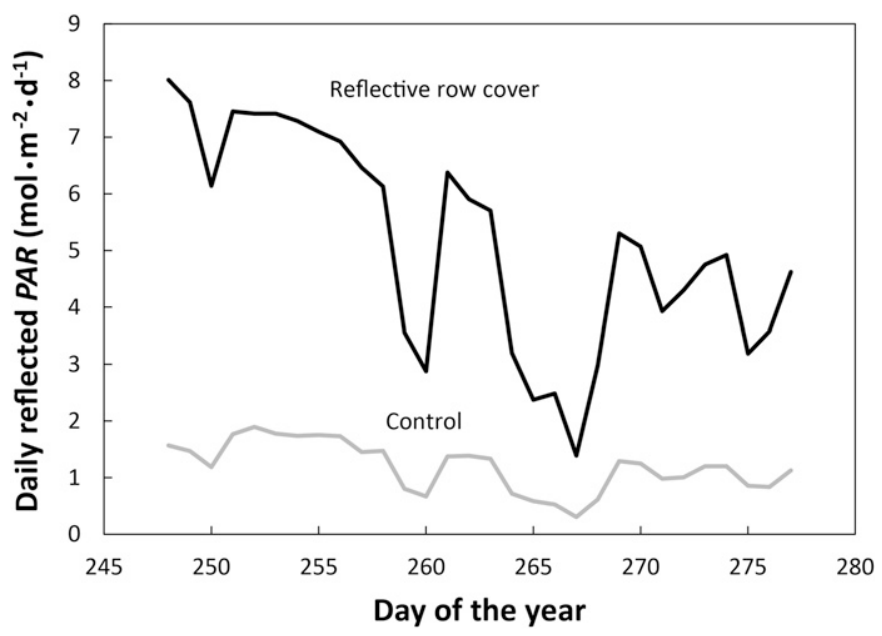

Fig. 2. Daily total reflected photosynthetically active radiation $(P A R)$ measured over the duration of the reflective rowcover treatment experiment in a commercial 'Ambrosia' apple orchard in Sept. 2014. Measurements were made with a quantum sensor (LI-190; LI-COR, Lincoln, NE) at $1 \mathrm{~m}$ height in the canopy of the trees and directed at a $45^{\circ}$ angle toward the middle of the adjacent row in both a block where reflective rowcover was applied and in a control block, where no rowcover was applied.

in regard to $P A R$ was reported previously with the application of this rowcover in an apple orchard (Privé et al., 2008). The UVA + UVB reflectance has also been recently reported to be enhanced by several fold in the reflective rowcover treatment vs. the control treatment (Toivonen et al., 2018).

Color space measurements allowed for direct comparison of the blush color development of apples from field treatments to apples exposed to the various wavelengths tested within the controlled environment chamber experiments. Reflective rowcover treatment resulted in the equivalent color space, as did exposure to $0.5 \mu \mathrm{mol} \cdot \mathrm{m}^{-2} \cdot \mathrm{s}^{-1}$ of UVB light for $5 \mathrm{~d}$ in the 
controlled environment chamber (Fig. 3). This is not surprising because Dong et al. (1995) demonstrated that postharvest UVB induction of red blush could mimic red blush color in the orchard. The apples from the orchard control treatment closely resembled the blush of apples exposed to $32 \mu \mathrm{mol} \cdot \mathrm{m}^{-2} \cdot \mathrm{s}^{-1}$ of UVA for $14 \mathrm{~d}$ within the controlled environment chamber (Fig. 3). The chamber fluorescent treatment was midway between the orchard control and the reflective rowcover treatments (Fig. 3). Finally, the visible-light-only treatment was at the opposite range of the color space from the reflective rowcover treatment color (Fig. 3). These results suggest that the major driver for red blush color development in Ambrosia apple, in orchards with reflective rowcovers, was UVB light. This observation is further supported by the fact that at harvest, the apples in the reflective rowcover treatment had been exposed to temperatures below $17^{\circ} \mathrm{C}$ for $121 \mathrm{~h}$ (data not shown), which is a similar to the $5 \mathrm{~d}$ or $120 \mathrm{~h}$ that the apples had been exposed to continuous UVB at $16^{\circ} \mathrm{C}$ in the growth chamber.

Although surface blush produced on poorly colored apples after exposure to UVB in the growth chamber mimicked the red blush that developed in the orchard with reflective rowcover treatment, there was also some color development after exposure to UVA (Fig. 3). This equivalency in color suggests that the control row would have been exposed to significant levels of UVA but little or no UVB (Fig. 1). The UVB waveband is not shown in the inset of Fig. 1, but viewing the trends seen in UVA band and referring to UVA + UVB light reflectance measures reported by Toivonen et al. (2018) may be reasonable to extrapolate that there would have been comparatively little or no UVB reflected into the canopy of the control treatments, whereas there would have been significant amounts reflected into the canopy of the reflective rowcover treatment. The response to red blush color development in the orchard control or the UVA chamber treatments was not surprising as it

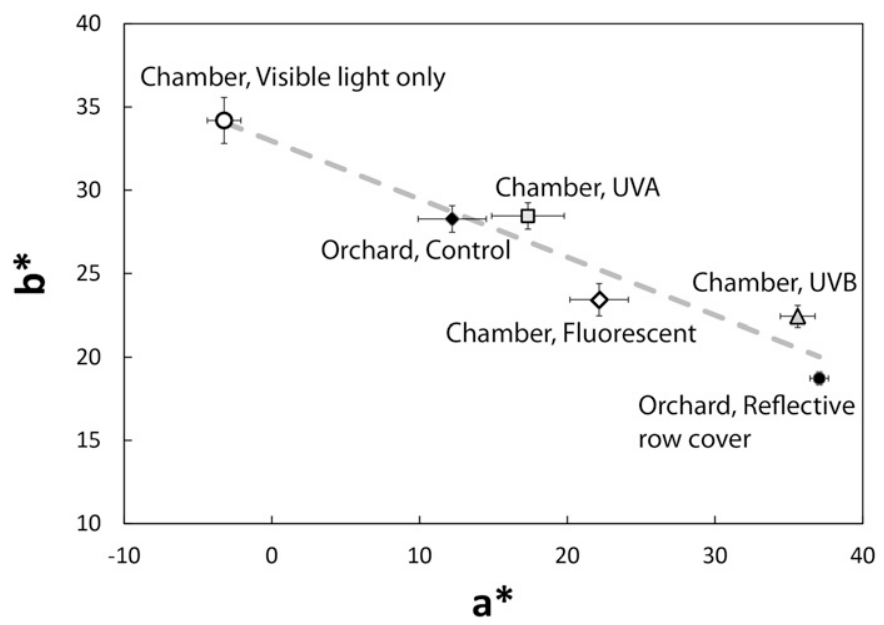

Fig. 3. A two-dimensional color space plot indicating the mean position that six light treatments occupied in that color space $(\mathrm{n}=15)$. Treatments in the orchard were control (not having any reflective rowcover) and reflective rowcover. Treatments applied in a growth chamber were 1) visible light only (ultraviolet blocked by a polycarbonate glass lens); 2) ultraviolet (UV) A, where 32 $\mu \mathrm{mol} \cdot \mathrm{m}^{-2} \cdot \mathrm{s}^{-1}$ was applied for $14 \mathrm{~d} ; 3$ ) fluorescent light that exposed the apple to visible light and a mixture of UVA and UVB light at a combine flux density of $1.5 \mu \mathrm{mol} \cdot \mathrm{m}^{-2} \cdot \mathrm{s}^{-1}$ was applied for $14 \mathrm{~d}$; and 4$) \mathrm{UVB}$, where $0.5 \mu \mathrm{mol} \cdot \mathrm{m}^{-2} \cdot \mathrm{s}^{-1}$ was applied for $5 \mathrm{~d}$. Vertical and horizontal error bars represent SE of $\mathrm{b}^{*}$ and $\mathrm{a}^{*}$ coordinate values for each treatment mean in the color space. 
has been found that UVA is much less effective in inducing anthocyanin biosynthesis (Middleton and Teramura, 1994). Exposure to fluorescent light in the controlled environment chamber experiment resulted in an intermediate development
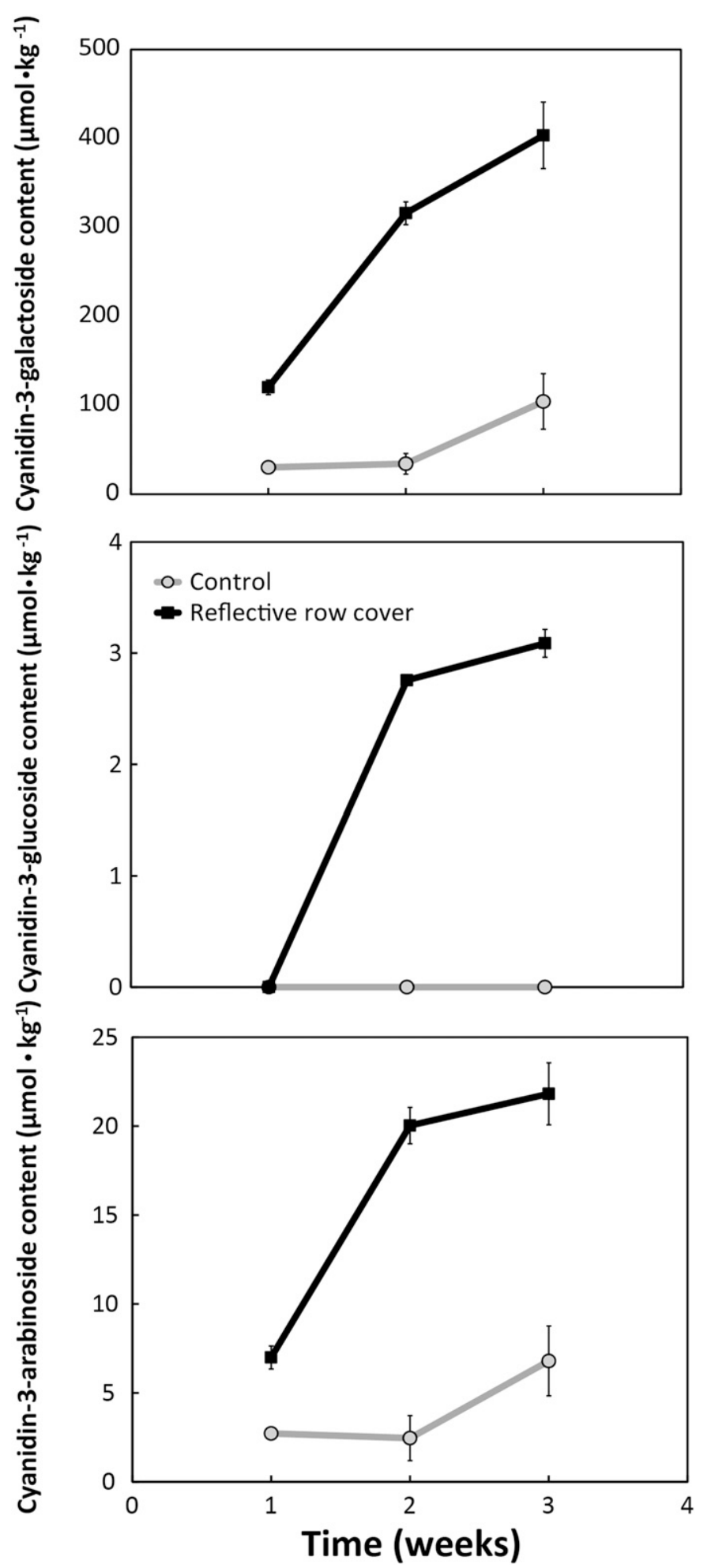

Fig. 4. Accumulation of three anthocyanin components over 3 weeks of applied reflective rowcover treatments in a commercial 'Ambrosia' apple orchard in Cawston, BC, Canada during Sept. 2014. Data points represent the mean $\pm \mathrm{SE}$ of three replicates each consisting of six apples. of color in the 'Ambrosia' apple peel (Fig. 3), and this was not surprising because fluorescent tubes are known to emit some UVB and higher levels of UVA (Klein et al., 2009), accounting for this intermediate response. Finally, the treatment receiving
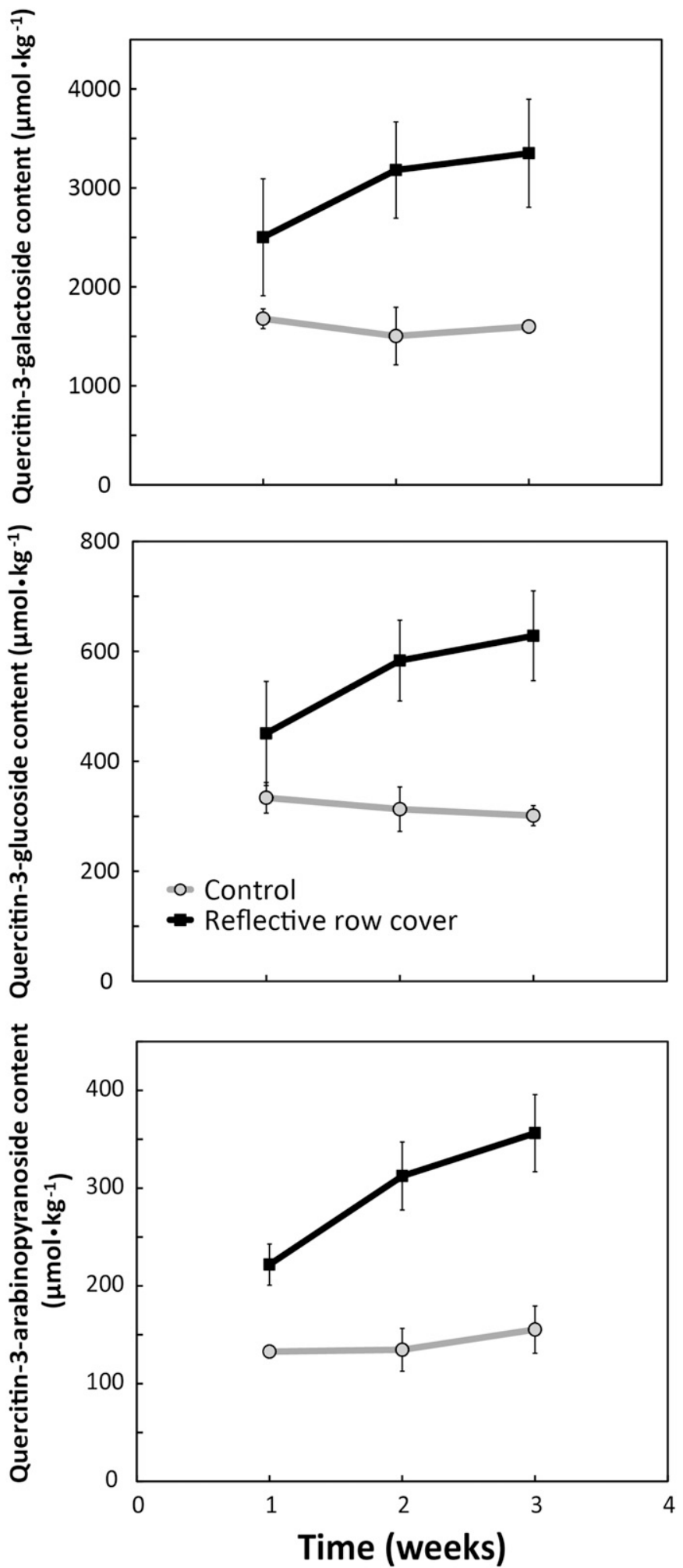

Fig. 5. Accumulation of three flavonol compounds over 3 weeks of applied reflective rowcover treatments in a commercial 'Ambrosia' apple orchard in Cawston, BC, Canada during Sept. 2014. Data points represent the mean $\pm \mathrm{SE}$ of three replicates each consisting of six apples. 
exposure to only visible light showed no development of red color even after $14 \mathrm{~d}$ (Fig. 3).

Biosynthesis of three anthocyanin components was significantly enhanced with the reflective rowcover treatment over 3 weeks of treatment (Table 1, Fig. 4). Cyanidin3 -galactoside contents were much higher than the glucoside and arabinoside derivatives of cyanidin (Fig. 4) which agrees with prior literature for other apple cultivars (Tsao et al., 2003).

Flavonol accumulation was significantly increased with the reflective rowcover treatment, but there was no consistent significant increase over time of measurement (Table 1, Fig. 5). The flavonol biosynthetic pathway shares many of its first reactions with the anthocyanin pathway, with the enzymes $\mathrm{CHS}, \mathrm{CHI}$, and $\mathrm{F} 3 \mathrm{H}$ in common. All of these increases in expression with treatment allow the accumulation of both anthocyanins and flavonols. However, the significant increase in the later anthocyaninspecific pathway (DFR, LDOX, and UFGT) would be expected to reduce the flow into flavonol synthesis.

The level of expression of the anthocyanin pathway in apple skin is largely controlled by changes in gene expression regulated by a MYB transcription factor (Ban et al., 2007; Espley et al., 2007; Takos et al., 2006). Because light and temperature both contribute to MYB1 regulation, the effect of reflective rowcovers on color development would include changes in expression of this transcription factor. Six genes in the anthocyanin pathway (CHS, CHI, F3H, DFR, LDOX, and UFGT) were shown to be coordinately upregulated in the reflective rowcover (Extenday) treatments compared with the controls. All genes had a significant difference in expression at the 3week point and several genes were already different after just 2 weeks (Fig. 6). The concomitant twofold difference in MYB1 levels was significant for week 3 but not for week 2. One other apple MYB gene (here designated MYB8 according to Cao et al., 2013) was tested and shown to increase significantly in the week 3 but showed no difference between rowcover treatments. This MYB was one of the first discovered in apple and was also named MYB1, which has created confusion in the literature. It is most similar to the Arabidopsis
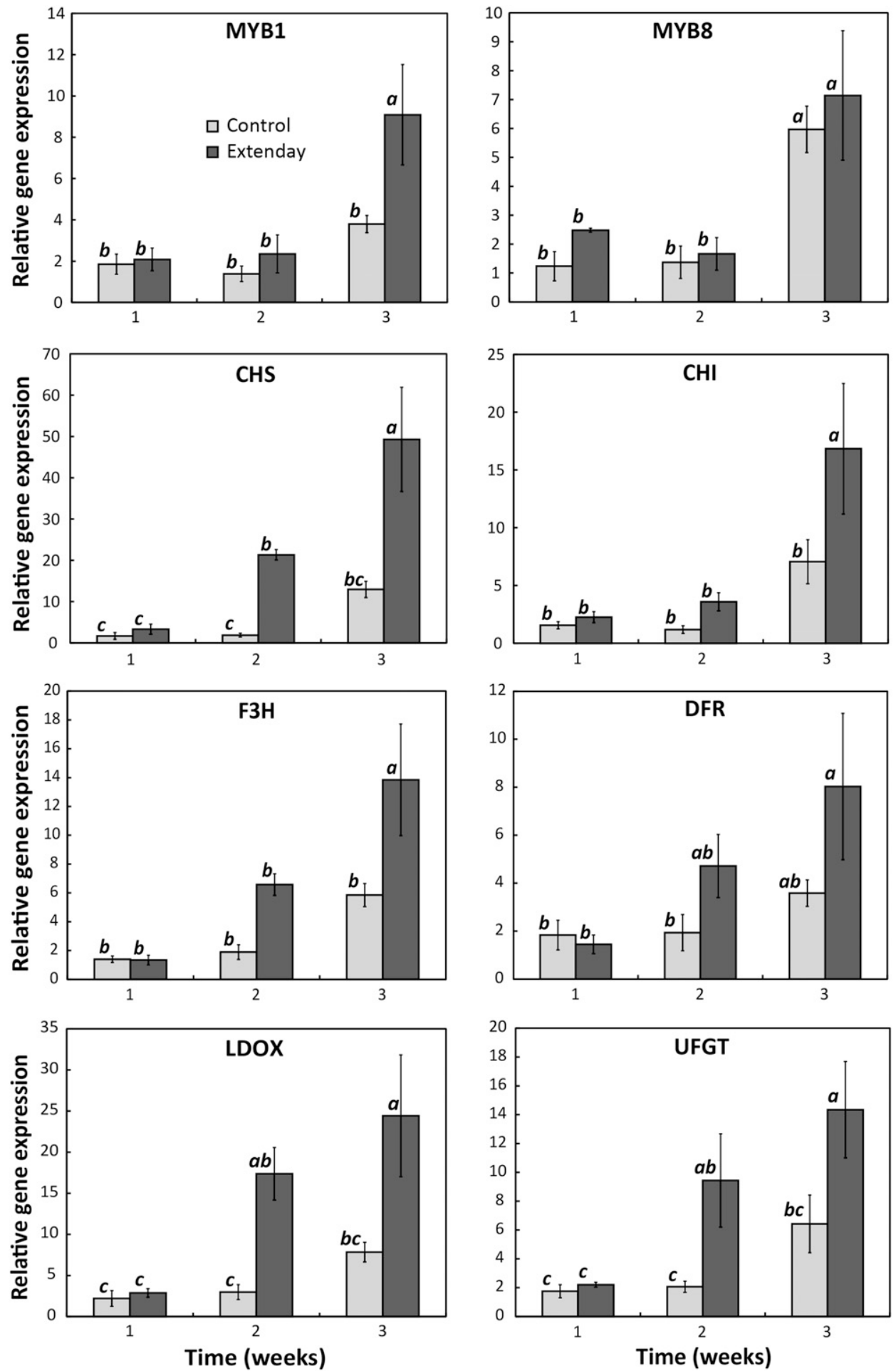

Fig. 6. Relative expression for six genes involved with mediating ultraviolet light-induced enhancement of anthocyanin biosynthesis. Rates of expression are relative to an internal standard of actin.
MYB1 (in a clade with AtMYB109, ATMYB25, and OsMYB1), which has been shown to be upregulated in response to abiotic stresses (Deeba et al., 2017). The commercial grower reported that irrigation was turned off in the experimental orchard 4 weeks before the final samples were collected, so it is possible that the increased expression for this apple MYB was due to water stress and/or heat stress. 
Additional genes known to be involved in anthocyanin pathway signaling were also tested but showed no significant changes in transcript levels (data not shown). These included the transcription factors MdbHLH3 and MdbHLH33, which have been shown to interact with MYB1 in promoter binding (Espley et al., 2007) and components of the UVB response pathway UVR8, COP1, and HY5. None of these genes were significantly changed in transcript level during the 3 weeks of the experiment nor did they differ between treatments. This suggests that MYB1 transcript increase is a main factor in anthocyanin stimulation, whereas regulation by UVR8, COP1, and HY5 may be at the level of protein interaction, nuclear localization, and/or protein degradation, which are not reflected in the transcript-level analysis. MYB1 alleles have been implicated in different anthocyanin accumulation profiles. Ambrosia has a MYB1-1, MYB1-2 genotype, with MYB1-1 predominating in skin color and MYB1-2 thought to be associated with epigenetic regulation and expression of this gene when fruit bagging with the cultivar Mutsu (Bai et al., 2016).

In conclusion, it is well known that UVB is the waveband having the greatest effect on anthocyanin biosynthesis (Middleton and Teramura, 1994; Reay and Lancaster, 2001; Ubi et al., 2006). This knowledge, along with the data presented in this article, both support the hypothesis that the reflective rowcover action on enhancing red blush color development in 'Ambrosia' apple is to significantly increase exposure of incanopy apples to UVB light.

\section{Literature Cited}

Bai, S., P.A. Tuan, T. Saito, C. Honda, Y. Hatsuyama, A. Ito, and T. Moriguchi. 2016. Epigenetic regulation of MdMYB1 is associated with paper bagging-induced red pigmentation of apples. Planta 244:573-586.

Ban, Y., C. Honda, Y. Hatsuyama, M. Igarashi, H. Bessho, and T. Moriguchi. 2007. Isolation and functional analysis of a MYB transcription factor gene that is a key regulator for the development of red coloration in apple skin. Plant Cell Physiol. 48:958-970.

Bassett, C.L. and D.M. Glenn. 2014. Reflective films and expression of light-regulated genes in field-grown apple. J. Amer. Soc. Hort. Sci. 139:487-494.

Blanpied, G.D. and K.J. Silsby. 1992. Predicting harvest date windows for apples. Cornell Coop. Ext. Info. Bul. 221.

Borges, G., A. Degeneve, W. Mullen, and A. Crozier. 2010. Identification of flavonoid and phenolic antioxidants in black currants, blueberries, raspberries, red currants, and cranberries. J. Agr. Food Chem. 58:3901-3909.

Cao, Z.-H., S.-Z. Zhang, R.-K. Wang, R.-F. Zhang, and Y.J. Hao. 2013. Genome wide analysis of the apple MYB transcription factor family allows the identification of MdoMYB121 gene conferring abiotic stress tolerance in plants. PLoS One 8(7):e69955, doi: 10.1371/journal.pone.0069955.

Castañeda-Ovando, A., M.D.L. Pacheco-Hernández, M.E. PáezHernández, J.A. Rodríguez, and C.A. Galán-Vidal. 2009. Chemical studies of anthocyanins: A review. Food Chem. 113:859-871.

Cline, J.A. 2009. Commercial production of Ambrosia apples in Ontario. AGDEX 211(32):1-8.

Deeba, F., T. Sultana, B. Javaid, T. Mahmood, and S.M.S. Naqvi. 2017. Molecular characterization of a MYB protein from Oryza sativa for its role in abiotic stress tolerance. Braz. Arch. Biol. Technol. 60:e17160352, doi: 10.1590/1678-4324-2017160352.

Dong, Y.H., D. Mitra, A. Kootstra, C. Lister, and J. Lancaster. 1995. Postharvest stimulation of skin color in Royal Gala apple. J. Amer. Soc. Hort. Sci. 120:95-100.
Espley, R.V., R.P. Hellens, J. Putterill, D.E. Stevenson, S. KuttyAmma, and A.C. Allan. 2007. Red colouration in apple fruit is due to the activity of the MYB transcription factor, MdMYB10. Plant J. 49:414-427.

Klein, R.S., V.P. Werth, J.C. Dowdy, and R.M. Sayre. 2009. Analysis of compact fluorescent bulbs for use by patients with photosensitive conditions. Photochem. Photobiol. 85:1004-1010.

Kollias, N., E. Ruvolo, Jr., and R.M. Sayre. 2011. The value of the ratio of UVA to UVB in sunlight. Photochem. Photobiol. 87:1474-1475.

Konica Minolta. 2017. Identifying color differences using $\mathrm{L}^{*} \mathrm{a}^{*} \mathrm{~b}^{*}$ or L*C*H* coordinates. 6 Apr. $2017<$ http://sensing.konicaminolta.us/ 2014/04/identifying-color-differences-using-l-a-b-or-1-c-h-coordinates/>. Kviklienė, N., D. Kviklys, and J. Lanauskas. 2008. Harvest time effect on quality changes of apple cultivar 'Alva' during ripening and storage. Scientific Works Lithuanian Inst. Hort. Lithuanian Univ. Agr. 27:3-8.

Middleton, E.M. and A.H. Teramura. 1994. Understanding photosynthesis, pigment and growth responses of UV-B and UV-A irradiances. Photochem. Photobiol. 60:38-45.

Pfaffl, M.W. 2001. A new mathematical model for relative quantification in real-time RT-PCR. Nucleic Acids Res. 29:2002-2007.

Privé, J.P., L. Russell, and A. Leblanc. 2008. Use of Extenday reflective groundcover in production of 'Gala' apples (Malus domestica) in New Brunswick, Canada: 1. Impact on canopy microclimate and leaf gas exchange. N. Z. J. Crop Hortic. Sci. 36:221-231.

Reay, P.F. and J.E. Lancaster. 2001. Accumulation of anthocyanins and quercetin glycosides in 'Gala' and 'Royal Gala' apple fruit skin with UV-B-Visible irradiation: Modifying effects of fruit maturity, fruit side, and temperature. Scientia Hort. 90:57-68.

Ritenour, M. and K. Habib. 1997. Red color development of apple: A literature review. 21 Nov. 2018. <http://postharvest.tfrec.wsu.edu/ rep2007a.pdf>.

Singh, S., S.B. Agrawal, and M. Agrawal. 2014. UVR8 mediated plant protective responses under low UV-B radiation leading to photosynthetic acclimation. J. Photochem. Photobiol. Bol. Biol. 137:67-76.

Solovchenko, A. 2010. Localization of screening pigments within plant cells and tissues, p. 67-88. In: A. Solovchenko (ed.). Photoprotection in plants: Optical screening-based mechanisms. SpringerVerlag, Heidelberg, Germany.

Takos, A.M., F.W. Jaffé, S.R. Jacob, J. Bogs, S.P. Robinson, and A.R. Walker. 2006. Light-induced expression of a MYB gene regulates anthocyanin biosynthesis in red apples. Plant Physiol. 142:1216-1232.

Toivonen, P., C. Lu, and J. Stoochnoff. 2018. Postharvest quality implications of pre-harvest treatments applied to enhance Ambro$\mathrm{sia}^{\mathrm{TM}}$ apple red blush color at harvest. Can. J. Plant Sci., doi: 10.1139/ CJPS-2018-0193.

Tsao, R., R. Yang, J.C. Young, and H. Zhu. 2003. Polyphenolic profiles in eight apple cultivars using high-performance liquid chromatography (HPLC). J. Agr. Food Chem. 51:6347-6353.

Ubi, B.E., C. Honda, H. Bessho, S. Kondo, M. Wada, S. Kobayashi, and T. Moriguchi. 2006. Expression analysis of anthocyanin biosynthetic genes in apple skin: Effect of UV-B and temperature. Plant Sci. 170:571-578.

Wiersma, P.A., H. Zhang, C. Lu, A. Quail, and P.M.A. Toivonen. 2007. Survey of the expression of genes for ethylene synthesis and perception during maturation and ripening of 'Sunrise' and 'Golden Delicious' apple fruit. Postharvest Biol. Technol. 44:204-211.

Wolfe, K., X. Wu, and R.H. Liu. 2003. Antioxidant activity of apple peels. J. Agr. Food Chem. 51:609-614.

Yin, R., M.Y. Skvortsova, S. Loubéry, and R. Ulm. 2016. COP1 is required for UV-B-induced nuclear accumulation of the UVR8 photoreceptor. Proc. Natl. Acad. Sci. USA 113:E4415-E4422.

Zhang, X.J., L.X. Wang, X.X. Chen, Y.L. Liu, R. Meng, Y.J. Wang, and Z.Y. Zhao. 2014. A and MdMYB1 allele-specific markers controlling apple (Malus $x$ domestica Borkh.) skin color and suitability for marker-assisted selection. Genet. Mol. Res. 13:9103-9114. 